\title{
Saint-Affrique et communes voisines
}

\section{Michel Maillé}

URL : http://journals.openedition.org/adlfi/17258

ISSN : 2114-0502

Éditeur

Ministère de la culture

Référence électronique

Michel Maillé, "Saint-Affrique et communes voisines », ADLFI. Archéologie de la France - Informations [En ligne], Midi-Pyrénées, mis en ligne le 03 mai 2016, consulté le 21 avril 2019. URL : http:// journals.openedition.org/adlfi/17258

Ce document a été généré automatiquement le 21 avril 2019

(C) Ministère de la Culture et de la Communication, CNRS 


\title{
Saint-Affrique et communes voisines
}

\author{
Michel Maillé
}

Lien Atlas (MCC) :

http://atlas.patrimoines.culture.fr/atlas/trunk/index.php?

ap_theme=DOM_2.01.02\&ap_bbox=2.755;43.904;2.952;44.010

1 Une mission d'actualisation de la base de données Patriarche de la commune de SaintAffrique nous avait été prescrite lors de notre autorisation de prospection pour 2013. L'objectif était de retrouver et positionner les sites archéologiques connus. Nous avons pu mettre à jour le positionnement d'une trentaine de sites de cette commune mais aussi quelques-uns situés sur des communes limitrophes. Les premières vérifications ont immédiatement démontré que plusieurs références cadastrales étaient erronées, de même pour les coordonnées géographiques ou planimétriques. La visite des sites connus a aussi permis de faire quelques constats sur leur état et compléter leur description. Un site probable a été découvert, un dolmen signalé très anciennement et porté disparu a été retrouvé.

2 Ce travail s'est déroulé en plusieurs étapes. Dans un premier temps il a fallu dépouiller la documentation, puis retrouver sur le terrain les sites et enfin réaliser un travail de positionnement sur carte et plans cadastraux. Le positionnement très précis des sites archéologiques est un élément indispensable à la meilleure gestion du patrimoine.

3 Pour chaque site, un point GPS a été relevé et des photographies ont été prises. Les coordonnées géographiques relevées ont été transformées en coordonnées planimétriques (L93 CC44) au moyen du logiciel gratuit de l'IGN : CIRCE. Ces coordonnées ont ensuite été reportées sur le site Internet cadastre.gouv. afin de retrouver la parcelle cadastrale et sa position sur la parcelle. Une vérification a été réalisée sur le terrain au moyen d'un smartphone équipé d'un GPS et affichant le cadastre en temps réel. 
Quelques sites et nouvelles découvertes : le bois de Laumière (commune de Saint-Rome de Cernon) compte trois dolmens en partie ruinés et les vestiges d'un habitat aggloméré. Les bâtiments semblent rectangulaires, semi-enterrés, l'appareillage des pierres montre deux phases distinctes. Une «enceinte» délimite partiellement le village, elle ne semble pas fermée. Ces ruines paraissent appartenir à un village médiéval.

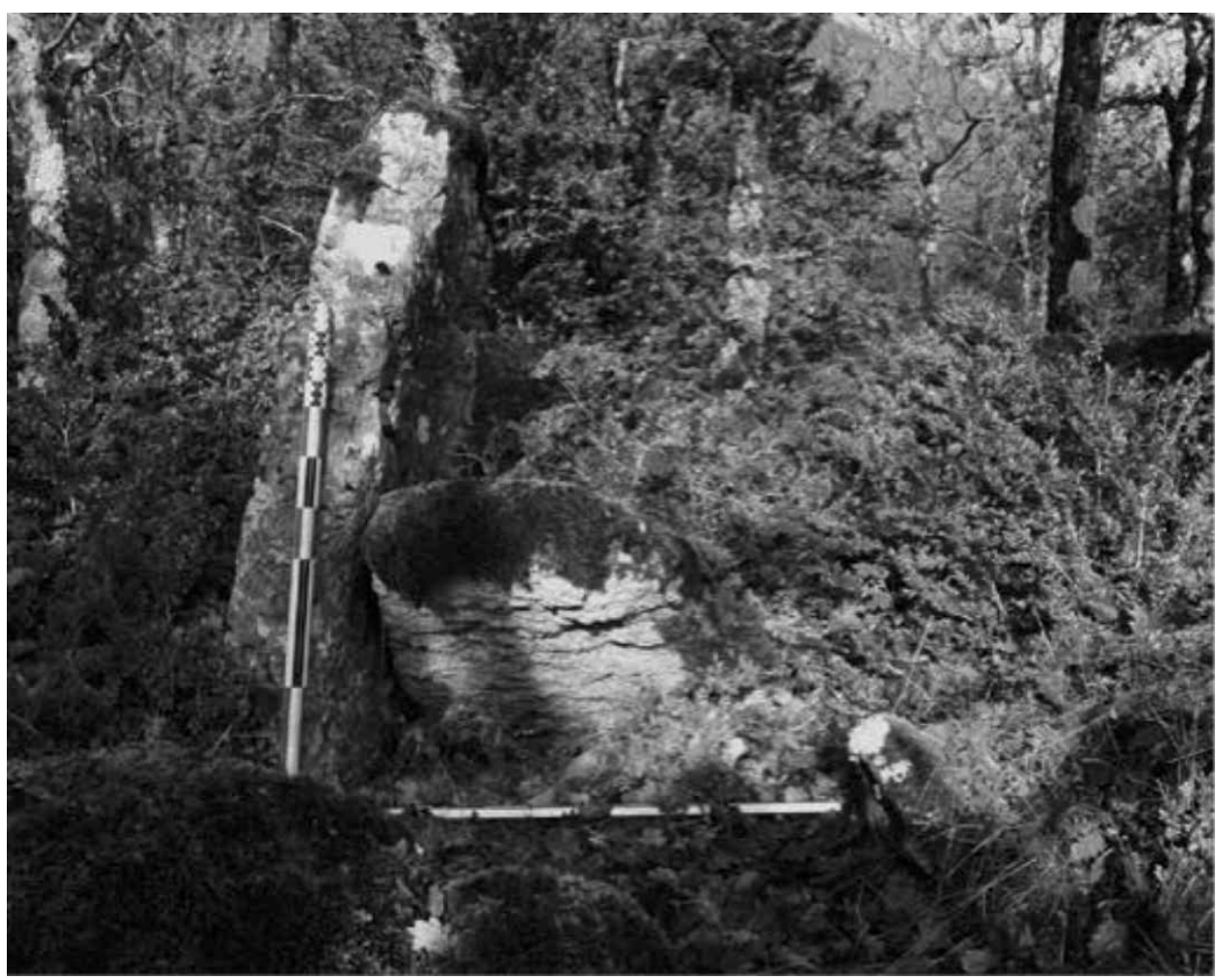

Fig 01

Dolmen de Pilandes sud : vue d'un montant ouest en position quasi verticale et de la dalle de chevet très inclinée.

5 Trois dolmens ont malheureusement été détruits : celui de Couriac, celui de la commune des Costes-Gozon, détruit anciennement mais dont il subsisterait des vestiges au sol; celui du Casse, commune de Saint-Rome de Tarn, détruit voici 4 ou 5 ans et celui de Puech Lagarde, commune des Costes-Gozon, détruit récemment. On peut ajouter le dolmen de Boussac-Est qui s'est effondré sur lui-même.

6 Lors de la visite du dolmen de Feriols, un dolmen situé à quelques centaines de mètres sur le site de la serre de Courbatières, commune de Saint-Jean D’Alcapiès, a été retrouvé. Ce dolmen est totalement ruiné mais il a conservé un vaste tumulus. Il n'était pas inconnu mais était porté disparu. Jean Poujol l'avait décrit ainsi : « Dolmens disparus. E - Le Serre : l'emplacement de ce dolmen correspondrait à un tènement situé entre les dolmens de Panel au Nord et la Cave del Rey au sud. Il est cité par Temple p. 87 de son inventaire."

7 Le dolmen de Pilandes sud est remarquable par son architecture, peu fréquente dans la région, car les montants latéraux sont composés de plusieurs piliers. Ces piliers et la dalle de chevet sont particulièrement élevés.

8 Enfin près du dolmen des Soutets et du site gallo-romain du même nom, une enceinte d'une centaine de mètres de diamètre a été repérée autour du sommet du Puech des 
Soutets. Elle est délimitée par un talus de terre et/ou de pierre conservé sur 1 à $2 \mathrm{~m}$ de hauteur.

INDEX

Mots-clés : dolmen, habitat, enceinte

operation Prospection inventaire (PI)

Index géographique : Midi-Pyrénées, Aveyron (12), Saint-Affrique

Index chronologique : âge du Fer

\section{AUTEURS}

MICHEL MAILLÉ

BEN 